Article

\title{
Towards a Model of Sustainable Competitiveness of Health Organizations
}

\author{
Simona Catalina Stefan *, Ion Popa and Cosmin Octavian Dobrin \\ Romania; iipopa@yahoo.com (I.P.); cdobrin@yahoo.com (C.O.D.) \\ * Correspondence: simonacatalina_2006@yahoo.com; Tel.: +40-721-423-269 \\ Academic Editor: Marc A. Rosen \\ Received: 18 February 2016; Accepted: 4 May 2016; Published: 11 May 2016
}

The Bucharest University of Economic Studies, Faculty of Management, Piata Romana 6, Bucharest 030173,

\begin{abstract}
Over the last decades, around the world, the concept of competitiveness was long debated by economists (and others), widely used and even sometimes overused. Although at the theoretical level, a number of determinant factors of health care organizations' competitiveness have been proposed, their diversity and the little empirical data available argues for the need to create and validate a model of competitiveness of health organizations. The purpose of this paper is (considering the theoretical approach) to shape a model of sustainable competitiveness of health organizations. In this respect, a 51 item questionnaire was designed and applied on a sample of 291 respondents from 12 Romanian health organizations. The exploratory factor analysis undertaken recovered more than $69 \%$ of the common variability of the initial 51 variables and revealed four factors/dimensions of sustainable competitiveness of health organizations (Economic Dimension, Quality Dimension, Social Dimension, and Strategic Dimension). Among the results of the exploratory factor analysis is also the empirical evidence on the contribution of leadership and managerial processes to enhance the influence of all other factors/dimensions in increasing the sustainable competitiveness of health organizations, thus bringing into focus the concept of sustainable management and leadership. Being just in the exploratory phase of our research, the proposed model can, and should, be improved, thus opening up further research directions.
\end{abstract}

Keywords: competitiveness; Factor Analysis; healthcare; leadership; management; sustainability

\section{Introduction}

This paper is part of a broader study, aiming to highlight the causal relationship between the particularities of the managerial tools employed within Romanian health organizations' managerial practice [1] and their level of competitiveness, in order to create premises for increasing the competitiveness and performances of Romanian organizations through the modernization of managerial tools.

Considering the complexity of the issue of competitiveness of healthcare organizations, we established two theoretical and empirical objectives, these being the main landmarks of the paper:

O1. The first objective was to synthesize the theoretical approaches concerning the issue of sustainable competitiveness and competitive advantage of health organizations, as well as their determinants.

O2. Considering the theoretical approaches, to shape the first form of the model of sustainable competitiveness of health organizations.

To achieve those objectives, the first part of the paper will deal with the theoretical approach while, in the second part, we will present and analyze the results of a pilot study aiming to be a first step in shaping a first form of the model of sustainable competitiveness of health organizations. 


\section{Theoretical Background}

\subsection{Approaches to the Concepts of Competitiveness and Corporate Sustainability}

Over the last decades, around the world, the concept of competitiveness was long debated by economists (and others) [2] (p. 1149), widely used, and even sometimes overused. Within the "Framework Conditions for Industrial Competitiveness", the OECD (Organization for Economic Co-operation and Development) Secretariat suggests that competitiveness should be understood as "the capacity of organizations, industries, regions and states in competition to provide in a sustainable way, a high efficiency of recovery factors of production and a higher income from labor exploitation" [3] (p. 20). This definition was subsequently taken over by various other OECD documents and enjoys wide acceptance.

Overall, competitiveness could be identified in terms of three levels of aggregation: competitiveness at the organizational level (firm-level competitiveness), the sector/industry level competitiveness, and the country/nation level competitiveness.

Competitiveness of a nation/country "has still no universally accepted definition, despite the widely use (sometimes abuse) of this concept. While it is clearly defined what means a competitive company/organization, not the same can be said about the notion of a competitive nation/country" [2] (p. 1149). Competitiveness of a nation/country refers to its ability to produce and distribute goods and services able to compete on the international market and, at the same time, an increase in real income and living standards of its citizens [4] (p. 63), [5]. Moreover, as stated by Banwet, Momaya, and Shee [6] (p. 133) it implies that the nation/country level competitiveness depends on the industry level and, ultimately, on firm level competitiveness. This relationship means that the competitiveness of a nation/country represents the effect, not the sum of the competitiveness levels of companies/organizations.

At the firm level, the concept of competitiveness is more clearly definable and generally widely accepted, relying mainly on the company's ability to compete on the free market, to grow, and be profitable. Firm/organization level competitiveness could be defined as "its ability to provide in relation to its competitors, products of value (quality) higher costs equal or of equal value at lower costs or a combination of these advantages and to achieve long-term economic performance" [7] (p. 141). Competitiveness is considered in the specialized literature as one of the essential dimensions of business performance [2] (p. 1149). Thus, according to Michael Porter [8] (pp. 4-12), business performances are determined by the attractiveness of the industry, the business competitive position within the industry, and its ability to maintain its competitive advantage, which is the key driver of business success or failure [9] (p. 15).

Another way to address competitiveness is the time perspective. Thus, the competitiveness of firms, industries, countries, etc., can be seen at a specific time (statically), through aspects such as market share, profitability, and position in international trade, or in the long-term (dynamically) [10] (p. 76). A similar approach, explored by Radu-Gherase [11], Radu, Grigore and Badea [12], and Radu [13] analyzes competitiveness from a dynamic perspective, stating that "competitiveness is both a result and a cause" [11] (p. 959); in other words, the future level of organization's competitiveness depends (among other factors) on its current level.

The concept of sustainable competitiveness is another way to address competitiveness from a time perspective. At the country level, it is defined as "the set of institutions, policies, and factors that determine the level of productivity of a country while ensuring the ability of future generations to meet their own needs" [14] (p. 54), while transposing to the business level, corporate sustainability could accordingly means "meeting the needs of firm's direct and indirect stakeholders without compromising its ability to meet the needs of future stakeholders as well" [15] (p. 131). In order to achieve the overall sustainable competitiveness, it is argued that managers should pay attention not only to economic sustainability of their firms, but also to social and ecological dimensions $[15,16]$. The concept of corporate sustainability is also symbolized in the literature by "triple P (planet, people, 
and profit)" [17]. For each of the three dimensions, there are described a number of aspects. Hence, the aspects of the economic dimension of corporate sustainability are [16,18]: collaboration, innovation and technology, knowledge management, purchase, processes, sustainability reporting, economic performance, financial health, and potential financial benefits. The social corporate sustainability aims at meeting both present and future needs of internal and external stakeholders, and is characterized by a number of aspects as $[16,18]$ : corporate governance, human capital development, motivation and incentives, health and safety, ethical behavior and human rights, no corruption and cartels, no controversial activities, corporate citizenship, internal human resources, and stakeholder participation. It is suggested that the outcomes from those various impacts need to be addressed simultaneously and in an integrated manner in order to achieve a sustainable competitive advantage [17].

\subsection{Sustainable Competitiveness of Health Organizations}

Competitiveness of health organizations, in a broad sense, is an advantage obtained over other organizations within the industry, by means of superior financial performance, efficient use of resources, an effective management system, under the influence of several internal and external factors (economic, financial, social, etc.) [19] (p. 27).

Particularly in health care, the issue of competitiveness should be analyzed based on the overall concept but also considering the peculiarities of this important area of economic and social life [20] (p. 16), and can be determined by a number of aspects found in the quality of health services, performance improvement, medical technologies, human resources management, substantiation methods of medical decision, prevention strategies, and increased quality of life [20] (p. 16).

Although, at first glance, the concept of competitiveness appears simple, the large number of determinant variables, the specific characteristics of health services "market", and the environmental factors which affect it, the complexity, difficulty, and even impossibility to measure them in some circumstances make it difficult to incorporate all aspects of theoretical models of analysis with a high degree of accuracy [21] (p. 1121), therefore, requiring further investigation of the variables involved.

Competitiveness is a potential, being analyzed in terms of competitive advantage expected and achieved by the organization. According to Michael Porter's concept, essentially, competitive advantage may relate either to a low cost of products or services or their differentiation, in one or more aspects, compared to competitors' products. Considering the specifics of the market in healthcare and particular aspects of the competition, the health organization's competitive advantage represents the delivery of high-quality health services compared with those provided by other organizations, so appreciated by patients, the public opinion, and public administration; thus could be considered competitive advantages of health organizations: high quality of medical services provided (in all defining aspects: accessibility, reliability, competence, continuity, compliance, etc.), medical endowment with high performance equipment, the use of modern medical products and new therapeutic procedures, comfortable conditions and lower rates, a reduced cost of services provided, etc. Human capital also plays an important role [22] (p. 64) in the reputation, professionalism, and courtesy of specialists within the organization.

The superior value over competitors mentioned in most definitions of competitiveness is that perceived by the customer. A global trend indicates that there is a change needed in health care systems by refocusing the emphasis on value for patients [23] (p. 132), meaning the transition from "zero-sum competition" [24] (p. 6), which is based on dividing the value and transfer costs between competitors, to "positive sum competition" that creates and increases value for the patient. Thus, competing on results, on the value added for patient per unit of cost, is the only meaningful way to ensure both the success of healthcare organizations on the particular healthcare market and meet the patients' needs. 


\subsection{Towards a Model of Sustainable Competitiveness of Health Organizations}

Although at the theoretical level, over time, there have been proposed a number of determinant factors of health care organizations' competitiveness, their diversity, and the little empirical data available, argues for the need to create and validate, based on empirical research, of a model of competitiveness of health organizations.

In this respect, we should mention the research of Rakhimbekova and Seitkaziyeva [19], who proposed an integral index of competitiveness of health care institution as a weighted average (by means of expert method) of six groups of factors related to: (1) infrastructure and resources capacity; (2) staffing; (3) innovation and research provision; (4) financial and economic support; (5) marketing and external relations; and (6) medical services.

Other authors [23,25] stress the importance of the balanced scorecard in increasing the competitiveness of private healthcare organizations. They conducted a survey on 36 managers and 184 patients of private healthcare organizations revealing that the most important competitiveness factors from the managers' perspective are: patient and public appreciation, resource base of medical professionals and technological equipment and, from the patients' point of view, the precise identification of patients' problems, health care service availability, and service quality.

Gowen III, McFadden, and Tallon [26], analyzing questionnaire data from the quality and/or risk directors of 587 US hospitals, have demonstrated the significant positive impact of quality management practices (which include: supplier quality evaluation, statistical quality/process control, evaluation of patient satisfaction, competitive benchmarking, and supply chain management) and strategic human resources management (employee quality teams, sharing of best-practices/information, employee financial rewards, training programs, employee recognition, and employee promotion opportunities) on sustainable competitive advantage of healthcare organizations.

\section{Materials and Methods}

\subsection{Research Design}

In the period April-May 2015, we conducted a pilot study with three main objectives: (1) to test the questionnaire in order to improve it for the main study; (2) to check the codification of questions, the import of data series in SPSS, and organization of the database; and (3) if the quality and quantity of data obtained on this occasion proved to be satisfactory, to achieve our next objective, namely shaping the first form of the competitiveness model of health organizations.

Since we assumed a reluctance to participate in such studies and in order to improve the response rate, we have chosen a "face to face" survey, which involved moving to the organization and assisting respondents to complete the questionnaire. Among the advantages of this type of investigation for the pilot study, we can include: (1) increased rate of completing the questionnaires, and (2) the possibility of takeover by interviewers of feedback needed to improve the questionnaire.

\subsection{Sampling}

The initial sample frame was 400 respondents from 12 healthcare organizations (selected through a convenience sampling method), of which 291 actually participated in the survey. This yielded a response rate of $72.75 \%$ which, in our opinion, could be considered very high. The demographic profile of the 291 respondents and characteristics of organizations investigated are presented in Table 1. 
Table 1. The sample structure.

\begin{tabular}{|c|c|c|c|c|c|}
\hline Characteristics & Share in the San & & Characteristics & Share in the Sample & \\
\hline \multirow{3}{*}{ Country region } & South-East & $14.09 \%$ & \multirow{6}{*}{ Profession } & Physicians & $29.21 \%$ \\
\hline & South & $32.99 \%$ & & Other medical staff with & $1271 \%$ \\
\hline & Bucharest-Ilfov & $52.92 \%$ & & $\begin{array}{l}\text { higher education } \\
\text { Nurses }\end{array}$ & $31.62 \%$ \\
\hline \multirow{4}{*}{$\begin{array}{l}\text { Organizations' age } \\
\text { (years) }\end{array}$} & Less than 5 & $0.00 \%$ & & Non-medical staff with & $15.81 \%$ \\
\hline & $10-15$ & $10.65 \%$ & & Non-medical staff with & \\
\hline & $15-20$ & $4.81 \%$ & & secondary education & $10.65 \%$ \\
\hline & Over 20 & $74.57 \%$ & \multirow{5}{*}{ Education } & High school & $13.40 \%$ \\
\hline \multirow{4}{*}{$\begin{array}{l}\text { Organizations' size } \\
\text { (employees) }\end{array}$} & Less than 10 & $0.00 \%$ & & College & $18.56 \%$ \\
\hline & $10-49$ & $37.46 \%$ & & Bachelor degree & $41.92 \%$ \\
\hline & $50-249$ & $37.11 \%$ & & Master & $20.96 \%$ \\
\hline & More than 250 & $25.43 \%$ & & $\mathrm{PhD}$ & $5.15 \%$ \\
\hline \multirow{4}{*}{$\begin{array}{l}\text { Seniority within } \\
\text { organization (years) }\end{array}$} & Less than 5 & $20.96 \%$ & \multirow{4}{*}{$\begin{array}{l}\text { Management } \\
\text { level }\end{array}$} & Top-level managers & 8.595 \\
\hline & $5-10$ & $42.61 \%$ & & Middle-level managers & $16.49 \%$ \\
\hline & $10-15$ & $16.84 \%$ & & First-line managers & $15.12 \%$ \\
\hline & More than 15 & $19.59 \%$ & & Executants & $59.79 \%$ \\
\hline
\end{tabular}

Source: Own representation based on survey data.

\subsection{Items}

Two methods were adopted for item generation: review of the existing literature and expert interviews. First, we conducted an extensive literature review on the subject of sustainability and competitiveness of health organizations, as well as their component factors, presented in Section 2 of this paper. Unfortunately, the result was not very encouraging since we have not found enough specific evidence in order to generate a questionnaire able to cover all of the possible component factors of sustainable competitiveness of health organizations. Therefore, we extended the area of our search, including references that approaching organizations, in general, from which we extracted possible component factors that might be valid for health organizations. The draft list was completed and reviewed through expert interviews. Table 2 presents, in the second column, all of the 16 final component factors and corresponding references in the fifth column. Under each of the identified component factors was grouped several items in order to capture various characteristic aspects of each of them, so, the final number of items was 51.

Table 2. Conceptual framework of variables.

\begin{tabular}{|c|c|c|c|c|}
\hline No. & $\begin{array}{c}\text { Factor } \\
\text { Components }\end{array}$ & No. of Items & Variables & References \\
\hline 1 & Human resources & 4 & $\begin{array}{l}\text { HR_1-Staffing, } \\
\text { HR_2-Human resources development, } \\
\text { HR_3-Staff competencies, } \\
\text { HR_4-Staff involvement }\end{array}$ & {$[6,16,18-20,23,25-27]$} \\
\hline 2 & $\begin{array}{l}\text { Financial } \\
\text { resources }\end{array}$ & 5 & $\begin{array}{l}\text { FR_1_Provision of financial resources, } \\
\text { FR_2-Efficient management of financial resources, } \\
\text { FR_3—Efficient management of financial resources, } \\
\text { FR_4-Cost of medical services, } \\
\text { FR_5-Investments }\end{array}$ & {$[19,23,25,27]$} \\
\hline 3 & $\begin{array}{l}\text { Technical } \\
\text { resources and } \\
\text { technologies }\end{array}$ & 2 & $\begin{array}{l}\text { TR_1-Technical resources, } \\
\text { TR_2-New technologies }\end{array}$ & {$[6,16,19,23,25,27]$} \\
\hline
\end{tabular}


Table 2. Cont.

\begin{tabular}{|c|c|c|c|c|}
\hline No. & $\begin{array}{c}\text { Factor } \\
\text { Components }\end{array}$ & No. of Items & Variables & References \\
\hline 4 & $\begin{array}{l}\text { Informational } \\
\text { resources }\end{array}$ & 2 & $\begin{array}{l}\text { IR_1-Provision of informational resources, } \\
\text { IR_2_Efficient management of informational resources }\end{array}$ & {$[19,27]$} \\
\hline 5 & Infrastructure & 1 & IN_1-Infrastructure & {$[6,19,27]$} \\
\hline 6 & $\begin{array}{l}\text { Material } \\
\text { resources }\end{array}$ & 3 & $\begin{array}{l}\text { MR_1-Provision of material resources, } \\
\text { MR_2-Efficient management of material resources, } \\
\text { MR_3-Consideration of patients' needs }\end{array}$ & {$[19,23,25,27]$} \\
\hline 7 & $\begin{array}{l}\text { Management and } \\
\text { leadership }\end{array}$ & 5 & $\begin{array}{l}\text { ML_1-Development of mission, vision and values, } \\
\text { ML_2-Performance management, } \\
\text { ML_3-Employee motivation, } \\
\text { ML_4-Relationships with stakeholders, } \\
\text { ML_5-Leadership }\end{array}$ & [27] \\
\hline 8 & $\begin{array}{l}\text { Strategy and } \\
\text { planning }\end{array}$ & 4 & $\begin{array}{l}\text { SP_1-Substantiation of strategy, } \\
\text { SP_2-Development of strategy, } \\
\text { SP_3-Implementation of strategy, } \\
\text { SP_4-Control of strategy }\end{array}$ & {$[23,24,27]$} \\
\hline 9 & Innovation & 2 & $\begin{array}{l}\text { INV_1-Implementation of innovative } \\
\text { medical processes, } \\
\text { INV_2-Transfer of know how }\end{array}$ & {$[6,16,19,27]$} \\
\hline 10 & $\begin{array}{l}\text { Organizational } \\
\text { change }\end{array}$ & 3 & $\begin{array}{l}\text { SCH_1-Planning the changes, } \\
\text { SCH_2-Implementing the changes, } \\
\text { SCH_3-Control of changes }\end{array}$ & {$[6,27]$} \\
\hline 11 & $\begin{array}{l}\text { Quality of health } \\
\text { services }\end{array}$ & 8 & $\begin{array}{l}\text { QS_1-Professional competence, } \\
\text { QS_2-Accessibility, } \\
\text { QS_3-Interpersonal relationships, } \\
\text { QS_4-Continuity of care, } \\
\text { QS_5-Efficiency, } \\
\text { QS_6-Effectiveness, } \\
\text { QS_7-Safety, } \\
\text { QS_8-Free choice }\end{array}$ & {$[6,19,20,23-26,28]$} \\
\hline 13 & $\begin{array}{c}\text { Patient } \\
\text { satisfaction }\end{array}$ & 3 & $\begin{array}{l}\text { PS_1-Evaluation of patient satisfaction, } \\
\text { PS_2-Patient satisfaction compared with } \\
\text { last evaluation, } \\
\text { PS_3-Patient satisfaction compared with that of } \\
\text { main competitors }\end{array}$ & {$[6,23,25,26]$} \\
\hline 14 & $\begin{array}{l}\text { Quality of life for } \\
\text { patients }\end{array}$ & 1 & QL_1-Quality of life for patients & {$[20,24,27]$} \\
\hline 15 & $\begin{array}{c}\text { Economic } \\
\text { performances }\end{array}$ & 3 & $\begin{array}{l}\text { EP_1-Economic performances compared with that of } \\
\text { main competitors, } \\
\text { EP_2_Economic performances compared with five } \\
\text { years ago, } \\
\text { EP_3-Economic performances compared with } \\
\text { objectives set }\end{array}$ & {$[6,18,19,23,25,27]$} \\
\hline 16 & Market share & 1 & MKS_1-Market share & [19] \\
\hline
\end{tabular}

Source: Own representation based on above mentioned references.

\subsection{Instrument}

The questionnaire was divided into three parts. Part I contained questions concerning the demographic profile of the respondents and characteristics of organizations investigated. Part II comprised of 20 questions and tried to capture specific-use management tools within the organization [1] (p. 793). Part III included a number of 16 questions and served the most direct purpose of this research. Concretely, this part of the questionnaire includes 14 questions corresponding to possible factor components of competitiveness of health organizations, grouping under each of them several items able to capture various characteristic aspects of each factor component. As mentioned 
above, in this paper we will focus only on analyzing the responses to the questions concerning this issue.

Each statement (question) was evaluated by the 291 subjects on a five-point Likert scale, ranging from 1-strongly disagree to 5-strongly agree.

For each of the sections, the number of questions was chosen so as to be sufficiently large to ensure the collection of necessary information and, on the other hand, be sufficiently small to increase the rate of completing the questionnaires and reduce as much as possible the non-responses.

The questionnaire was preceded by a preamble/invitation, which included information on the aim of the research. The respondents were ensured about the confidentiality of information gathered and that they will not be used only for scientific purposes. Additionally, it was noted that the decision to provide respondents a glossary that defines/explains the key concepts of the questionnaire proved to be of a real interest among respondents, helping them in completing the questionnaire.

Reliability and validity were investigated. To check the internal consistency reliability, Cronbach's alpha [29] coefficient of reliability was computed. In our case, the Cronbach's alpha coefficient value of 0.980 was well above the threshold of 0.70 [30], meaning that there is evidence that the individual indicators measure the same underlying construct [2] (p. 1153). To support construct validity, factor analysis was used to determine the underlying constructs able to explain as much as possible the variance of the initial set of variables.

\subsection{Data Analysis}

Considering we are in the exploratory phase of our research, and wishing to shape a first form of the competitiveness model of health organizations, unveiling the latent structure of the 51 variables measured by our 51 items questionnaire, the logical choice was exploratory factor analysis (EFA).

Now, having selected the variables, we should decide on the factor extraction method. Basically, there are two such methods available: principal component analysis (PCA) and factor analysis (FA). While there are obvious differences between PCA and FA, it has not yet reached a consensus on which of them is more suitable to be used for EFA. Therefore, we relied our decision on two criteria [31]: (1) the research objectives, and (2) the amount of prior knowledge about the variance of the variables. Considering that our main objective is to detect the underlying construct represented in the original dataset, and we have a little knowledge on the amount of specific and error variance, wishing to eliminate them, we have chosen the factor analysis.

"Factor analysis is a multivariate analysis, which aims to explain the correlations manifested between a number of variables, called indicators or tests, using a smaller number of uncorrelated factors called common factors" [32] (p. 64). The model is given by [33]:

$$
\begin{array}{ccc}
X_{1}= & a_{11} F_{1}+a_{12} F_{2}+\cdots+a_{1 m} F_{m}+e_{1} \\
X_{2}= & a_{21} F_{1}+a_{22} F_{2}+\cdots+a_{2 m} F_{m}+e_{2} \\
\cdots \cdots \cdots+\cdots \\
X_{Q}= & a_{Q 1} F_{1}+a_{Q 2} F_{2}+\cdots+a_{Q m} F_{m}+e_{Q}
\end{array}
$$

where $X_{i}(i=1 \ldots Q)$ are the original variables; $a_{i 1}, a_{i 2}, \ldots, a_{i m}$ represent the factor loadings related to the variable $X_{i} ; F_{1}, F_{2}, \ldots F_{m}$ are $m$ uncorrelated common factors and $e_{i}$ are the $Q$ specific factors distributed identically, with zero mean and supposedly independently.

\section{Results}

\subsection{Preliminary Considerations}

First, we have determined if our dataset is suitable for EFA. Considering the 291 respondents (the suggested threshold for the sample size are 100 [31] and 300 [34]) and 51 variables, we have met the criteria of sample size and number of variables for every hypothesis latent structure to have at least five variables [31]. 
The Cronbach's alpha coefficient value of 0.980 (presented in the last row of Table 4), well above the threshold of 0.70 [30], means that there is evidence that the individual indicators measure the same underlying construct [2] ( p. 1153). A special attention was granted to the problem of multicollinearity, which would negatively impact on the EFA. For instance, some of the factors shown in Table 2 seem to have causal relationships (e.g., patient satisfaction leads to more patients, which can increase profitability and market share). In the correlation matrix, we have checked if there is a lack of patterned relationships among our variables or there is a problem with multicollinearity. In our dataset, there were no variables with a large number of low correlation coefficient $(r<+/-0.30)$ or above $r=+/-0.90$, indicating that we do not have such issues with our dataset. Moreover, as one can see in Table 3, the significant Bartlett's test of sphericity $\left(\chi^{2}=16073.540, p<0.01\right)$, the overall Kaiser-Meyer-Olkin measure of sampling adequacy above the cutoff of 0.50 [35] $(\mathrm{KMO}=0.930)$, and individual values (diagonal elements of the anti-image correlation matrix) above the cutoff of 0.50 , mean that our dataset is suitable for factor analysis.

Table 3. KMO and Bartlett's test.

\begin{tabular}{lcc}
\hline \multicolumn{2}{l}{ Kaiser-Meyer-Olkin Measure of Sampling Adequacy } & $\mathbf{0 . 9 3 0}$ \\
\hline & Approx. Chi-Square & $16,073.540$ \\
Bartlett's test of sphericity & df & 1275 \\
& Sig. & 0.000 \\
\hline
\end{tabular}

Source: Made by authors.

\subsection{Factor Extraction and Rotation}

As stated above, with the main objective to detect the underlying construct of the 51 variables concerning the competitiveness of health organizations, we have conducted an exploratory factor analysis (EFA) with a principal axis factoring extraction method and rotation method-Varimax with Kaiser Normalization.

The next decision to be taken was the number of extracted factors. We relied on four criteria: (1) Kaiser criterion which states that we should retain all the factors with eigenvalues greater than 1. This criterion is reliable when we deal with $20-50$ variables. If the number of variables is less than 20 , the tendency is to extract too few, and if there are more than 50 variables (as in our case) the tendency is to extract too many factors [31] (p. 108); (2) scree test. The scree plot is a graphical representation of the consecutive factors on the horizontal axis and eigenvalues on the vertical. The number of factors to retain is immediately before the spot in the plot where it abruptly levels out [36]; (3) percentage of variance explained. This approach aims to extract successive factor until a cumulative percentage of the total variance explained is achieved $(60 \%, 70 \%, 80 \%)$. For social sciences, it is not uncommon to consider solutions accounting 60\% [31] (p. 108); and (4) interpretability. All of the extracted factors (especially the last one) should be interpretable and describe the items as indicative of an underlying factor.

Considering the Kaiser criterion, seven factors with an eigenvalue greater than one were extracted. This first seven-factor solution was not considered appropriate since the last three factors did not meet the recommendation of Tabacknick and Fidell [34] that for something to be labeled as a factor, it should have at least three variables. On the other hand, the examination of the scree plot suggested a three-factor solution. In those circumstances, for the final decision, we examined solutions with three, four, five, six, and seven factors, considering the other two criteria, namely: percentage of variance explained and interpretability.

The final model computed with principal axis factoring as the extraction method and rotation method-Varimax with Kaiser Normalization recovers $69.009 \%$ of the common variability of all of the 51 original variables. 
Rotated factor matrix (see Table 4) presents the four-factor solution and the significant factor loadings for each of the factors. The loading is the correlation between the original variable and its factor and represents the amount of variable's total variance accounted for by the factor [35] (p. 116). With only two exceptions (ML_5-0.386 and MKS_1-0.338), all variables present factor loading above 0.50. Given the sample size of 291, we have considered a threshold of 0.30 [37] (p. 394) and all variables with factor loadings above this threshold were retained for further interpretation.

Table 4. Rotated Factor Matrix.

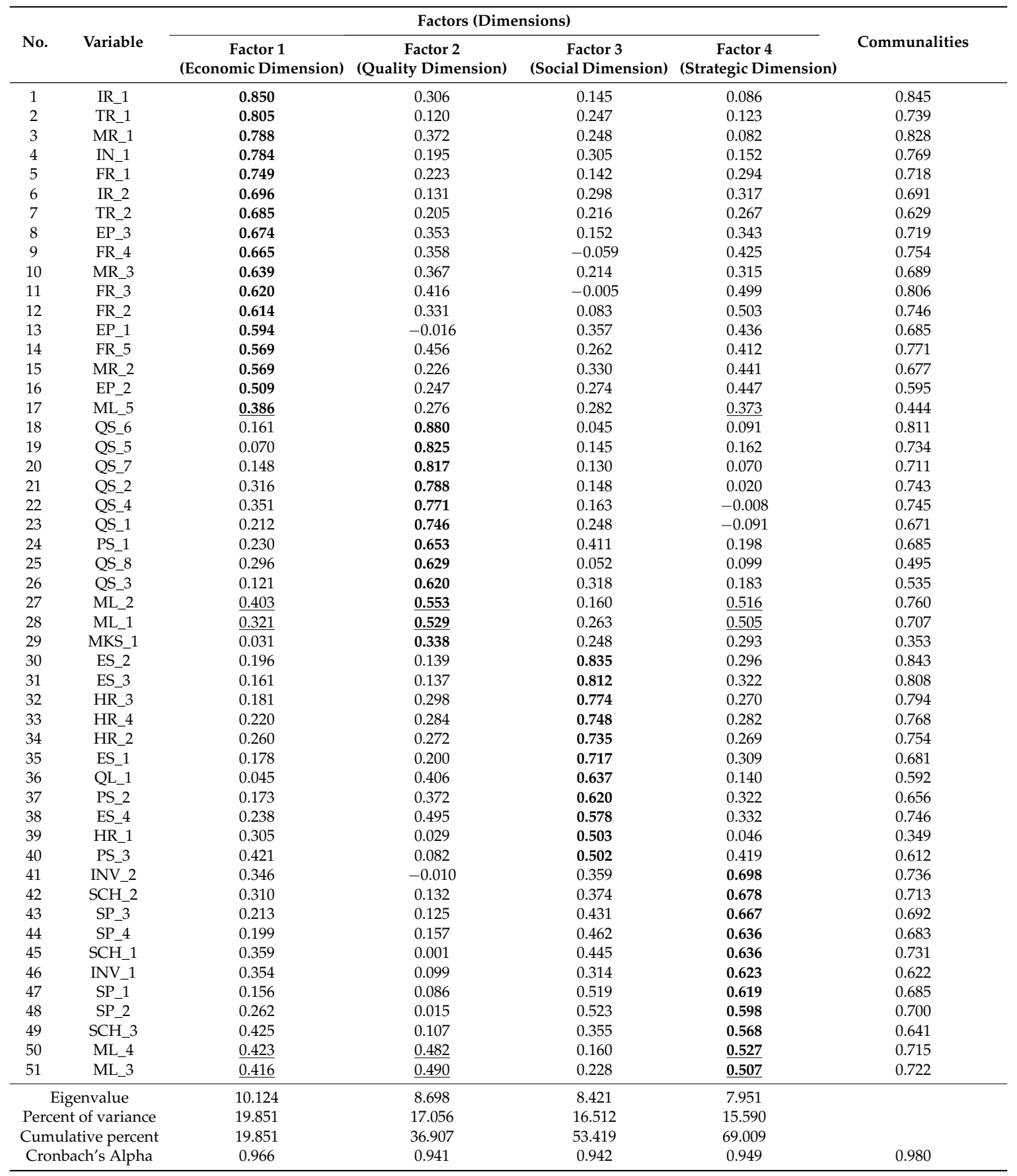

Extraction Method: principal axis factoring. Rotation Method: Varimax with Kaiser Normalization. a. Rotation converged in nine iterations. The bold numbers are the factor loadings (the correlation between each variable and its Factor/dimension); The underline numbers illustrate the contribution of the variables ML_1 ... ML_5 to more than one Factor. 
Examining the commonalities (presented in the last column of Table 4) we have noticed that two variables have lower values (ML_5-0.444 and MKS_1-0.353), but still above the threshold of 0.30 . One would consider deleting them but, finally, we decided to keep these two variables considering: (1) MKS_1 is the only variable measuring the market share (which is considered an important component of competitiveness), and (2) the factor solution obtained after deletion was not as suggestive as this one. These two variables (ML_5 and MKS_1) will be kept under observation in the future and will be considered the most appropriate solutions so as not to be a problem in the main survey.

The four-factor final solution could be considered a good fit since, looking at the reproduced correlation matrix, we found that the non-redundant residuals with absolute values greater than 0.05 are $<50 \%$ [2] (p. 1152). Additionally, Cronbach's alpha was calculated for each construct/factor/dimension to assess the internal consistency. All of the constructs reported good reliabilities ( 0.966 for Factor 1 , 0.941 for Factor 2, 0.942 for Factor 3, and 0.949 for Factor 4), well above the recommended minimum value of 0.70 . Therefore, the reliability of this instrument was also supported.

\section{Discussion}

\subsection{Identifying and Naming the Factors}

Having determined the number of retained factors, now we are concerned with their interpretation. This process is not as straightforward as it would seem to be at the first sight. The statistically significant loadings of initial variables on each of the extracted factors are taken into consideration, but so too are their capacity to gather together under some meaningful existing concepts.

We have to admit that, after the literature review, we would not expect such model of competitiveness of health organizations. However, looking to the results of factor analysis, things began to make sense and the model took its first shape. In Table 4 all 51 variables are presented and are significantly correlated with the four extracted factors, arranged in descending order of loading. Given the sample size of 291, we have considered a threshold of 0.30 [37] (p. 394) and all variables with factor loadings above were retained for further interpretation.

(1) Factor 1-Economic Dimension (the third column of the Table 4) cumulates $19.851 \%$ of the common variability of all the 51 original variables and is significant and positively correlated with the 17 variables related to: informational resources (IR_1-Provision of informational resources-0.850 and IR_2-Informational resources efficiency-0.696), technical resources and technologies (TR_1-Technical resources-0.805 and TR_2-New technologies-0.685), material resources (MR_1-Provision of material resources-0.788, MR_3 - Consideration of patients' needs— 0.639 and MR_2-Material resources efficiency-0.569), infrastructure (IN_1 - Infrastructure-0.784), financier resources (FR_1-Provision of financial resources-0.749, FR_4-Cost of medical services-0.665, FR_3-Financial resources efficiency-0.620, FR_2-Financial resources efficiency-0.614 and FR_5-Investments-0.569), economic performances (EP_3-Economic performances compared with objectives set-0.674, EP_1-Economic performances compared with that of main competitors-0.594 and EP_2-Economic performances compared with five years ago-0.509), and management and leadership (ML_5-Leadership-0.386); therefore, the most appropriate name to define it would be Economic Dimension. It is noted that, on this factor, loaded-together variables describe both economic resources and results.

(2) Factor 2-Quality Dimension (the fourth column of the Table 4) cumulates $17.056 \%$ of the common variability of all the 51 original variable and is significant and positively correlated with the 12 variables related to: quality of health services (QS_6-Effectiveness-0.880, QS_5-Efficiency-0.825, QS_7-Safety-0.817, QS_6-0.880, QS_2—Accessibility-0.788, QS_4-Continuity of care- 0.771 , QS_1—Professional competence- 0.746 , QS_8-Free choice- 0.629 and QS_3-Interpersonal relationships-0.620), patients' satisfaction (PS_1-Evaluation of patient 
satisfaction—0.653), management and leadership (ML_2—Performance management-0.553 and ML_1—Development of mission, vision and values-0.529), and market share (MKS_1—339); therefore, the most appropriate name to define it would be Quality Dimension.

(3) Factor 3-Social Dimension (the fifth column of the Table 4) cumulates $16.512 \%$ of the common variability of all the 51 original variable and is significant and positively correlated with the 11 variables related to: employee satisfaction (ES_2-Evaluation of employee insatisfaction-0.835, ES_3-Employee satisfaction compared with last evaluation-0.812, ES_1-Evaluation of employee satisfaction-0.717 and ES_4-Employee satisfaction compared with that of main competitors-0.578), human resources (HR_3-Staff competencies-0.774, HR_4-Staff involvement-0.748, HR_2—Human resources development-0.735 and HR_1—Staffing-0.503), patients' quality of life (QL_1-0.637) and patients' satisfaction (PS_2 - Patient satisfaction compared with last evaluation-0.620 and PS_3-Patient satisfaction compared with that of main competitors-0.502); therefore, the most appropriate name to define it would be Social Dimension. It is noted that, as in case of the Economic Dimension, on this factor loaded-together variables describe both human resources and social results.

(4) Factor 4-Strategic Dimension (the sixth column of the Table 4) cumulates $15.590 \%$ of the common variability of all the 51 original variable and is significant and positively correlated with the 11 variables related to: innovation (INV_2-Transfer of know-how-0.698 and INV_1-Implementation of innovative medical processes-0.623), organizational change (SCH_2-Implementing the changes-0.678, SCH_1-Planning the changes-0.623 and SCH_3 - Control of changes-0.568), strategy and planning (SP_3-Implementation of strategy-0.667, SP_4—Control of strategy-0.636, SP_1—Substantiation of strategy-0.619 and SP_2—Development of strategy-0.598) and management and leadership (ML_4-Relationships with stakeholders-0.527 and ML_3-Employee motivation-0.507); therefore, the most appropriate name to define it would be Strategic Dimension.

Analyzing data presented in Table 4, one may notice several variables that, besides the factor they belong to, load relatively strongly on another factor. As they could have considerable impact on the conceptual meaning of the factors identified, those situations will be discussed below: (1) it is natural that FR_5-Investments to load beside Factor 1-Economic Dimension, on Factor 2-Quality Dimension (0.456), alongside with Accessibility, Efficiency, Effectiveness, and Safety and Factor 4-Strategic Dimension (0.412). (2) QS_3-Interpersonal relationships between patients and medical staff are considered an important component of quality of medical services, therefore it is explainable why it loads on Factor 2-Quality Dimension, but also closely related to Social Dimension (Factor 3). (3) Evaluation of patient satisfaction (PS_1) is an essential component of quality management systems of health organizations (loads 0.653 on Factor 2-Quality Dimension) and conceptually related to the other factor components of the Social Dimension. (4) Another good example is INV_2-Transfer of know-how, which loads very strong on Factor 3-Strategic Dimension, but also on Factor 3-Social Dimension. There are also few examples of variables for which it is not so straightforward to explain the reason why they load on one or another factor. Therefore, they will be kept under observation and properly addressed on the main investigation.

A special consideration should be granted to the variables corresponding to the concepts of management and leadership (ML_1 ... ML_5). They seem to have significantly and almost equal loadings on three of the factors (Factor 1-Economic Dimension, Factor 2-Quality Dimension, and Factor 4-Strategic Dimension). Looking exclusively at the figures, one would conclude that this is a clear situation of cross-loading, and would decide to drop then. However, a competitiveness model without a managerial component would not make any sense. Therefore, on the contrary, we decided to keep those variables in our final solution, even more so if it is logical that every dimension of competitiveness is to include a managerial component. 


\subsection{Implications}

This first shape of the proposed model of sustainable competitiveness of health organizations may potentially have both theoretical and managerial implications.

Although most of the initial list of factor/dimension components was put together by reviewing existing literature on corporate sustainability and competitiveness of health organizations, their distribution in the final factor analysis solution gives the uniqueness of the model. It is also worth mentioning that it confirmed some of the theoretical approaches presented above. Thus, the Economic Dimension and the Social Dimension proved to be similar to those of the tri-dimensional concept of corporate sustainability (economic dimension, environmental dimension, and social dimension) [16,18]. Moreover, on the Factor 1-Economic Dimension and Factor 3-Social Dimension, variables describing both economic resources and economic results, load together significantly, in particular, human resources and social results, respectively.

The unexpected, but also meaningful contribution of variables corresponding to concepts of management and leadership to explain in almost equal extent three of the four factors/dimensions of competitiveness, puts the spotlight on the concepts of sustainable management and leadership. Thus, among the results of exploratory factor analysis are also the empirical evidence on the contribution of leadership and managerial processes to enhance the influence of all other factors/dimensions in increasing the sustainable competitiveness of health organizations.

As for managerial implications, managers of health organizations could benefit from the above findings in their efforts of gaining sustainable competitive advantage over similar institutions. Thus, their efforts should be primarily directed to providing necessary resources (informational resources, technical resources, material resources, infrastructure, and financial resources) and to their efficient management, according to patients' needs. An important component of sustainable competitiveness of health organizations is also the quality of medical services provided, translated primarily by: effectiveness, efficiency, safety, and accessibility. The research findings also suggest the significant contribution to the overall sustainable competitiveness of the other two identified factors/dimensions: Social Dimension and Strategic Dimension.

We have to mention that the above findings are limited to the population studied, namely health care organizations in Southeast Romania. In order for the proposed model of sustainable competitiveness of health organizations to be extrapolated at the country level, in the next stage of our research we will consider: (1) replication of the study on a nationally-representative sample (in terms of both the number of respondents and their geographical distribution); (2) improvement of the model by introducing other variables; (3) validation of research instruments using confirmatory factor analysis. As concerns the generalizability of this paper's findings, we doubt that the same four-dimension structure would emerge from factor analysis if applying the same research instrument to a population with different socio-cultural characteristics, under the influence of different economic factors $[38,39]$.

\section{Conclusions}

This study can present both theoretical and empirical implications. On the one hand, the comprehensive and rigorous review of the literature was undertaken, and was able to synthesize a significant amount of information to outline ways of achieving a consensus on debates and controversies and outline future research directions. On the other hand, the quantitative exploratory research carried out adds value to the theoretical approach, considering it is the first one which shaped a draft model of health organizations' competitiveness.

A 51 items questionnaire was designed and applied on a sample of 291 respondents from 12 Romanian health organizations. The final model was computed with a principal axis factoring extraction method and rotation method: Varimax with Kaiser Normalization recovers $69.009 \%$ of the common variability of all of the 51 original variables and revealed four factors/dimensions of sustainable competitiveness of health organizations (Material Dimension, Quality Dimension, Social Dimension, and Strategic Dimension). 
Among the results of the exploratory factor analysis is the empirical evidence on the contribution of leadership and managerial processes to enhance the influence of all other factors/dimensions in increasing the sustainable competitiveness of health organizations, thus bringing into focus the concept of sustainable management and leadership.

Needless to say, our proposed model of competitiveness of health organizations can, and should, be improved, especially since it resulted from a pilot study and we are just in the exploratory stage of our research, "aiming to establish the coordinates of a complex managerial phenomenon, to define variables and hypotheses which will represent the basis of further research" [40] (p. 60). We also assume some research limitations, mainly due to the character of the pilot study of our investigation: (1) a small and homogeneous sample; (2) replication of the study is needed; (3) application of varying factor analysis methods with oblique vs. orthogonal assumptions; and (4) use of a confirmatory factor analysis to validate the assessment instrument, thus opening up further research directions.

Author Contributions: Simona Catalina Stefan, Ion Popa and Cosmin Octavian Dobrin designed the study. Simona Catalina Stefan conducted the literature review, developed the questionnaire, analyzed the data and interpreted the results. Ion Popa and Cosmin Octavian Dobrin revised and finalized the questionnaire. Simona Catalina Stefan and Ion Popa collected the data. Ion Popa and Cosmin Octavian Dobrin assisted in interpreting the results. Simona Catalina Stefan, Ion Popa and Cosmin Octavian Dobrin wrote the paper. Ion Popa and Cosmin Octavian Dobrin revised the manuscript for intellectual content. All authors have read and approved the final manuscript.

Conflicts of Interest: The authors declare no conflict of interest.

\section{Abbreviations}

The following abbreviations are used in this manuscript:

OECD Organization for Economic Co-operation and Development

\section{References}

1. Popa, I.; Ștefan, S.C.; Popescu, D.I. A Pilot Study on Management Systems Implemented within Romanian Organizations. In Proceedings of the 26th IBIMA Conference-Innovation Management and Sustainable Economic Competitive Advantage: From Regional Development to Global Growth, Madrid, Spain, 11-12 November 2015; pp. 791-803.

2. Popa, I.; Ștefan, S.C. 'Why do some nations succeed and others fail in international competition?' Factor analysis and cluster analysis at European level. Ann. Univ. Oradea Econ. Sci. 2015, XXIV, 1149-1157.

3. OECD. Globalisation and Competitiveness: Relevant Indicators, 1996. Available online: http://www. oecd.org/officialdocuments/publicdisplaydocumentpdf/?cote=OCDE/GD\%2896\%2943\&docLanguage=En (accessed on 31 January 2015).

4. Blaine, M. Profitability and competitiveness: Lessons from japanesse and American firms in the 1980s. Calif. Manag. Rev. 1993, 3, 48-74. [CrossRef]

5. Scot, B.; Lodge, G. U.S. Competitiveness in the World Economy; Harvard Bussiness School Press: Boston, MA, USA, 1985.

6. Banwet, D.K.; Momaya, K.; Shee, H.K. Competitiveness through technology management: An empirical study of Indian software industry. Int. J. Serv. Technol. Manag. 2003, 4, 131-155. [CrossRef]

7. Nicolescu, O.; Verboncu, I.; Ionescu, G.; Russu, C.; Mihut, I.; Ilieș, L. Dicționar de Management; Pro Universitaria: Bucharest, Romania, 2011.

8. Porter, M.E. Competitive Advantage. Creating and Sustaining Superior Performance; Free Press: New York, NY, USA, 1985; pp. 4-12.

9. Porter, M.E. Avantajul Concurenţial. Manual de Supravieţuire şi Creştere a Firmelor în Condiţiile Economiei de Piaţă; Teora: Bucharest, Romania, 2001; p. 15.

10. Ioncică, M.; Petrescu, E.C.; Ioncică, D. Macro and microeconomic approaches to competitiveness in the services sector. Rev. Mark. Online 2008, 2, 76-82.

11. Radu-Gherase, C. The Influence of Leadership on Organization's Level of Competitiveness. Rev. Int. Comp. Manag. 2009, 10, 959-967. 
12. Radu, C.; Grigore, A.-M.; Badea, F. The Impact of Organizations' Potential of Competitiveness on Their Current Strategic and Tactical Movements. Ann. Univ. Oradea Econ. Sci. 2010, 997-1001.

13. Radu, C. Dezvoltarea Unui Model Pentru Analiza în Dinamică a Competitivităţii Organizaţiilor. Available online: http:/ / oeconomica.org.ro/abstract/345/Dezvoltarea-unui-model-pentru-analiza-\%C3\% AEn-dinamic\%C4\%83-a-competitivit \%C4\%83\%C5\%A3ii.html (accessed on 17 January 2016).

14. World Economic Forum. The Global Competitiveness Report 2011-2012; Geneva, 2011. Available online: http://www3.weforum.org/docs/WEF_GCR_Report_2011-12.pdf (accessed on 17 April 2016).

15. Dyllick, T.; Hockerts, K. Beyond the business case for corporate sustainability. Bus. Strategy Environ. 2002, 11, 130-141. [CrossRef]

16. Baumgartner, R.J.; Ebner, D. Corporate Sustainability Strategies: Sustainability Profi les and Maturity Levels. Sustain. Dev. 2010, 18, 76-89. [CrossRef]

17. Asif, M.; Searcy, C.; Zutshi, A.; Ahmad, N. An integrated management systems approach to corporate sustainability. Eur. Bus. Rev. 2011, 23, 353-367.

18. Brent, A.; Labuschagne, C. Social Indicators for Sustainable Project and Technology Life Cycle Management in the Process Industry. Int. J. Life Cycle Assess. 2006, 11, 3-15. [CrossRef]

19. Rakhimbekova, A.E.; Seitkaziyeva, A.M. Competitiveness of health care institutions of the Republic of Kazakhstan: Theory, evaluation technique, development mechanism. Life Sci. J. 2014, 11, 27-31.

20. Cicea, C.; Dobrin, C.; Popa, I. Competitivitatea în domeniul serviciilor de sănătate publică. Qual. Access Success 2009, 10, 16-22.

21. Radu, C.; Popescu, D. Strategic and Tactical Movements and Organizations' Competitiveness. In Annals of DAAAM; DAAAM International: Vienna, Austria, 2011; pp. 1121-1122.

22. Popa, I.; Dobrin, C.; Popescu, D.; Drăghici, M. Competitive Advantage in the Public Sector. Theor. Empir. Res. Urban Manag. 2011, 6, 60-66.

23. Mavlutova, I.; Babauska, S. The Competitiveness and Balanced Scorecard of Health Care Companies. Int. J. Synerg. Res. 2013, 2, 107-128.

24. Porter, M.E.; Teisberg, E.O. Redefining Health Care: Creating Value-Based Competition on Results; Harvard Business School Press: Boston, MA, USA, 2006.

25. Mavlutova, L.; Balauska, S. Latvian Health Care Company Competitiveness Determining Indicators and their Improvement Possibilities. J. Soc. Sci. 2012, I, 234-250.

26. Gowen, C.R., III; McFadden, K.L.; Tallon, W.J. On the centrality of strategic human resource management for healthcare quality results and competitive advantage. J. Manag. Dev. 2006, 25, 806-826. [CrossRef]

27. European Institute of Public Administration. The Common Assessment Framework 2013. Improving Public Organisations through Self-Assessment. Available online: http://www.eipa.eu/files/File/CAF/CAF_2013. pdf (accessed on 25 January 2016).

28. Donabedian, A. An Introduction to Quality Assurance in Health Care; Oxford University Press: New York, NY, USA, 2003.

29. Cronbach, L.J. Coefficient alpha and the internal structure of tests. Psychometrika 1951, 16, 297-334. [CrossRef]

30. Nunnaly, J.C.; Bernstein, I.R. Psychometric Theory, 3rd ed.; McGraw-Hill: New York, NY, USA, 1994.

31. Hair, J.F.; Black, W.C.; Bobin, B.J.; Anderson, N.E. Multivariate Data Analysis, 7th ed.; Pearson Prentice Hall: Upper Saddle River, NJ, USA, 2010.

32. Ruxanda, G. Analiza Multidimensională a Datelor-Suport de curs; Academia de Studii Economice, Școala Doctorală: Bucharest, Romania, 2009.

33. OECD. Handbook on Constructing Composite Indicators. Methodology and User Guide; OECD Publishing: Paris, France, 2008.

34. Tabacknick, B.G.; Fidell, L.S. Using Multivariate Statistics, 5th ed.; Allyn \& Bacon publisher: Boston, MA, USA, 2007.

35. Kaiser, H.F. A second-generation little jiffy. Psychometrika 1970, 35, 401-415. [CrossRef]

36. Paleologou, V.; Kontodimopoulos, N.; Stamouli, A.; Aletras, V.; Niakas, D. Developing and testing an instrument for identifying performance incentives in the Greek health care sector. BMC Health Serv. Res. 2006. [CrossRef] [PubMed]

37. Stevens, J.P. Applied Multivariate Statistics for the Social Sciences, 4th ed.; Erlbaum: Hillstade, NJ, USA, 2002.

38. Crăciun, L.; Năstase, M.; Stamule, T.; Vizitiu, C. Leadership in Romanian Small to Medium Enterprises. Sustainability 2015, 7, 4183-4198. [CrossRef] 
39. Rahman, M.N.A.; Doroodian, M.; Kamarulzaman, Y.; Muhamad, N. Designing and Validating a Model for Measuring Sustainability of Overall Innovation Capability of Small and Medium-Sized Enterprises. Sustainability 2015, 7, 537-562. [CrossRef]

40. Olteanu, V. Cercetări de Marketing; Editura Fundației “România de Mâine”: Bucharest, Romania, 2000.

(c) 2016 by the authors; licensee MDPI, Basel, Switzerland. This article is an open access article distributed under the terms and conditions of the Creative Commons Attribution (CC-BY) license (http:/ / creativecommons.org/licenses/by/4.0/). 